\title{
Tratamento térmico T6 modificado: uma proposta econômica para liga Al 7075
}

\author{
Mateus Giacomini Dariva \\ Instituto Federal do Rio Grande do Sul (IFRS) Sul - Campus Feliz \\ (mateusdariva@hotmail.com) \\ Cinthia Gabriely Zimmer \\ Instituto Federal do Rio Grande do Sul (IFRS) Sul - Campus Feliz \\ (cinthia.zimmer@feliz.ffrs.edu.br)
}

\begin{abstract}
Resumo: A liga de alumínio Al 7075 é uma das mais utilizadas nas indústrias bélica e aeronáutica, onde a combinação de alta resistência mecânica e baixo peso específico são requisitos fundamentais. Para atingir a resistência máxima, essas ligas devem ser tratadas termicamente pelo processo de solubilização e envelhecimento. $\mathrm{O}$ tratamento denominado T6, recomendado para essa liga segundo a literatura, consiste em solubilizar e após envelhecer a liga à $120^{\circ} \mathrm{C}$ pelo período de 24 horas. Em um ambiente industrial esse tempo acaba sendo um entrave no sistema produtivo. Sendo assim, o objetivo desse trabalho é a avaliação das propriedades microestrutural e de dureza da liga submetida ao tratamento T6 modificado, pela redução do tempo e aumento na temperatura do tratamento. Para tanto, amostras de Al 7075 provenientes do processo de laminação e forjaria foram solubilizadas na temperatura de $470^{\circ} \mathrm{C}$ pelo tempo de 2 horas e então resfriadas bruscamente em água. Após, essas amostras foram envelhecidas a $200^{\circ} \mathrm{C}$ pelo tempo de 4 horas. Os resultados mostraram que o envelhecimento sob temperatura elevada e tempo reduzido proporcionou precipitados finamente dispersos na matriz, de forma homogênea e com pouca ocorrência nos contornos de grão. Esse resultado vai ao encontro com os resultados considerados ideais para resistência máxima, contudo observou-se também a formação de precipitados do tipo $\theta$, que evidenciam que o material começou entrar na fase de superenvelhecimento, 0 qual promove a redução das propriedades mecânicas. A dureza do material apresentou resultados compatíveis com a dureza obtida pelo tratamento convencional. Conclui-se que a proposta de modificação do tratamento T6 é uma alternativa mais rápida e econômica para o processo de envelhecimento, onde conseguiuse a redução do tempo de processo, com possibilidade de aplicação onde a dureza é o único requisito necessário.
\end{abstract}

Palavras-chave: Alumínio; Liga Al 7075; Tratamento Térmico; Envelhecimento.

\section{Modified heat treatment T6: an economic proposal for aluminum alloy}

Abstract: Aluminum alloy Al 7075 is one of the most used alloys in the military and aeronautics, were a high mechanical resistance and low specific weight are requested. To achieve maximum resistance, these alloys must be heat treated by solubilization and aging. The T6 named treatment, recommended by literature for this alloy, consists in solubilizing and aging the alloy at $120^{\circ} \mathrm{C}$ for 24 -hour period. At an industrial environment this time ends up being a problem in the productive system. Therefore, the objective of this article is the evaluation of the hardness and microstructural properties of the alloy subjected to a modified T6 heat treatment, by reduction of the exposure time and temperature increase. Al 7075 samples from rolling mill and forging were solubilized at $470^{\circ} \mathrm{C}$ for 2-hour and quenched in water at room temperature. After that, the samples were aged at $200^{\circ} \mathrm{C}$ for 4 -hour period. The results show that the aging process with high temperatures and reduced time delivers finely dispersed precipitates in the matrix, homogenous and with low occurrence at the grain boundary edges. These results are similar to ideal results expected for maximum resistance, however it was observed the formation of $\theta$ type precipitates, that shows that the material started to overaging, that promotes the reduction of the mechanical resistances. The hardness of the material showed compatible results obtained by conventional treatment. It is concluded that the proposal of the T6 modified treatment is a faster and economical alternative for the aging process, lowering the process time.

Keywords: Aluminum; Al 7075 alloy; Heat treatment; Aging. 


\section{INTRODUÇÃO}

As ligas Al 7075 (Al-Zn-Mg-Cu) foram introduzidas comercialmente no ano de 1943, paralelamente ao acontecimento da segunda guerra mundial e não por acaso, pois suas principais aplicações são justamente a indústria bélica e aeronáutica. Sua composição está apresentada na Tabela 1.

Tabela 1 - Composição da liga Al 7075 apresentada em porcentagem de massa (ZOU e colab., 2016).

\begin{tabular}{|c|c|c|c|c|c|c|c|c|c|}
\hline Elemento & $\mathrm{Zn}$ & $\mathrm{Mg}$ & $\mathrm{Cu}$ & $\mathrm{Cr}$ & $\mathrm{Ti}$ & $\mathrm{Mn}$ & $\mathrm{Si}$ & $\mathrm{Fe}$ & $\mathrm{Al}$ \\
\hline $\begin{array}{l}\% \quad \text { em } \\
\text { massa }\end{array}$ & $\begin{array}{l}5,1 \\
a \\
6,10\end{array}$ & $\begin{array}{l}2,1 \text { a } \\
2,9\end{array}$ & $\begin{array}{ll}1,2 & a \\
2,0 & \end{array}$ & $\begin{array}{l}0,18 \\
a \\
0,28\end{array}$ & 0,2 & 0,3 & 0,4 & 0,5 & Balanço \\
\hline
\end{tabular}

Esta composição proporciona a esta liga a maior resistência dentre todas as ligas de alumínio, pois elementos como cobre, silício e magnésio são adicionados para promover a formação de uma solução sólida e o endurecimento pela formação de precipitados após aplicação de tratamento térmico, além de favorecer a conformabilidade (HUANG, 2006). Devido a isto é utilizada em estruturas sob solicitações severas (ARAÚJO e colab., 2014). Sua alta resistência mecânica aliada a baixa densidade, torna o Alumínio 7075 amplamente utilizado na indústria aeroespacial, militar e indústria automotiva (ZOU e colab. 2016; LI e colab. 2008; CHEN e colab.2014).

Para aumentar a resistência mecânica dessa liga o tratamento térmico T6, denominado envelhecimento, é recomendado (ARAÚJO e colab., 2014). Porém, antes disso, é importante realizar o tratamento térmico de solubilização (ASM, 1992 a). Isso porque esse tratamento propicia a distribuição e tamanho de precipitados em um estado ideal para resistência máxima. Já o T6 proporciona endurecimento pela formação de precipitados coerentes, com dispersão fina e densa, em uma matriz dúctil e supersaturada (OLIVEIRA, 2012; ASM, 1992 b). Quanto menos espaçados e menores forem os precipitados, melhor será a resistência mecânica da liga, sem perda excessiva de ductilidade (SOUZA, 1982). O aumento da resistência mecânica é decorrente das barreiras geradas pelas partículas de precipitados, causando restrições ao movimento das discordâncias (SILVA, 2016). 
Quando os átomos do precipitado se ajustam perfeitamente aos átomos da matriz, diz-se que o precipitado é coerente com a matriz. Caso contrário, ele é incoerente e em casos intermediários, é semicoerente. A importância disso se dá pelo fato de a resistência da liga ser determinada, muitas vezes, em função da coerência do precipitado. Quando o precipitado perde a coerência, a resistência da liga não atinge seu potencial máximo (SOUZA, 1982).

A definição dos parâmetros para aplicação de um tratamento térmico resume-se em: temperatura, tempo de permanência e taxa de resfriamento. Essas informações são obtidas a partir dos diagramas de fase, curvas de tratamentos isotérmicos e gráficos obtidos a partir de testes que correlacionam padrões às propriedades.

Partindo do diagrama de fases mostrado na Figura 1, a solubilização da liga Al 7075 consiste em aquecer o metal até uma temperatura dentro do campo monofásico a e permanecer nessa temperatura até que toda fase seja completamente transformada. Geralmente aplica-se a temperatura de $470{ }^{\circ} \mathrm{C}$ pelo tempo de 2 horas. Esse procedimento é seguido de resfriamento rápido até a temperatura ambiente, para prevenir qualquer difusão ou formação de fase a (retida) (ARAÚJO e colab., 2014).

Figura 1 - Diagrama de fases da liga Al 7075 (KIECKOW e colab., 2017).

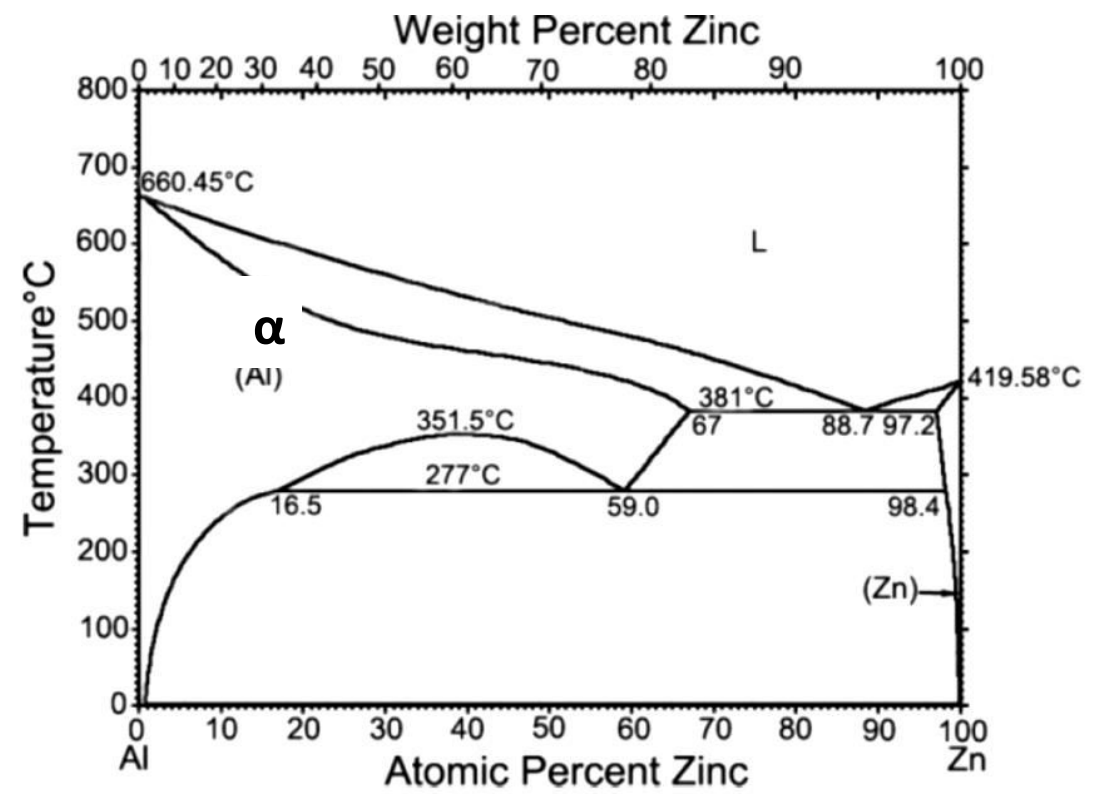

O envelhecimento do alumínio pode gerar diferentes tipos de precipitados, os quais são resultado da combinação tempo-temperatura. A Figura 2 representa de forma esquemática a base para a determinação adequada do tempo para o 
envelhecimento do alumínio, correlacionando a microestrutura a ser formada com a resistência mecânica e dureza.

Figura 2 - Representação da evolução da microestrutura, resistência mecânica e dureza em ligas de alumínio tratáveis termicamente, a uma temperatura constante [Adaptado de SMITH, 1998].

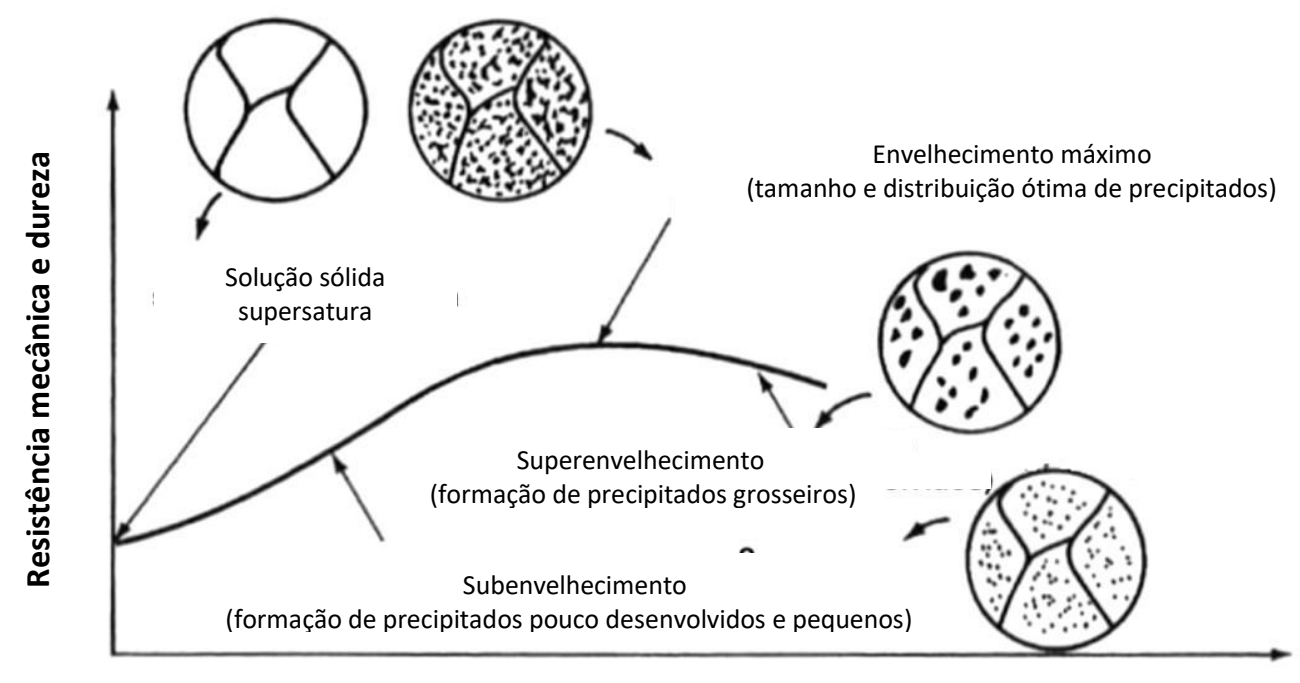

Tempo de envelhecimento à temperatura constante

Conforme mostra o gráfico da Figura 3, os melhores parâmetros de temperatura para obtenção de resistência máxima, de uma liga de alumínio, se encontram na faixa de temperatura entre $107^{\circ} \mathrm{C}$ e $150^{\circ} \mathrm{C}$, compreendido em um período de tempo de 20 a 30 horas. Contudo a aplicação de uma temperatura superior, por exemplo $190{ }^{\circ} \mathrm{C}$, propiciará aumento de dureza com a aplicação de um tempo menor (representado por linhas tracejadas).

Estas mudanças nas propriedades resultam devido a formação de domínios microestruturais ricos em soluto, ou Zonas Guinier-Preston (zonas GP) (ASM, 1992 b). As zonas GP são caracteristicamente metaestáveis e solubilizam na presença de precipitados mais estáveis. Sua estabilização se dá sob envelhecimentos com tempos mais longos e à baixas temperaturas. Tempos de envelhecimento curtos podem ocasionar a reversão das zonas GP, caso se completar antes da formação de $\theta^{\prime}$, que pode indicar nucleação heterogênea da fase $\theta$ (HEALEY, 1976). Esta fase é não coerente com a matriz e aparece na forma globular e de discos, geralmente se forma em contornos de grão (ASKELAND, 2008; PONTES, 2017). Quando a fase $\theta$ não-coerente precipitar, a resistência da liga diminui e se diz que a liga está na condição de superenvelhecida. 
Figura 3- Efeito do tempo e temperatura de envelhecimento no limite de escoamento da liga $\mathrm{Al}-4 \% \mathrm{Cu}$ (ASKELAND, 2008)

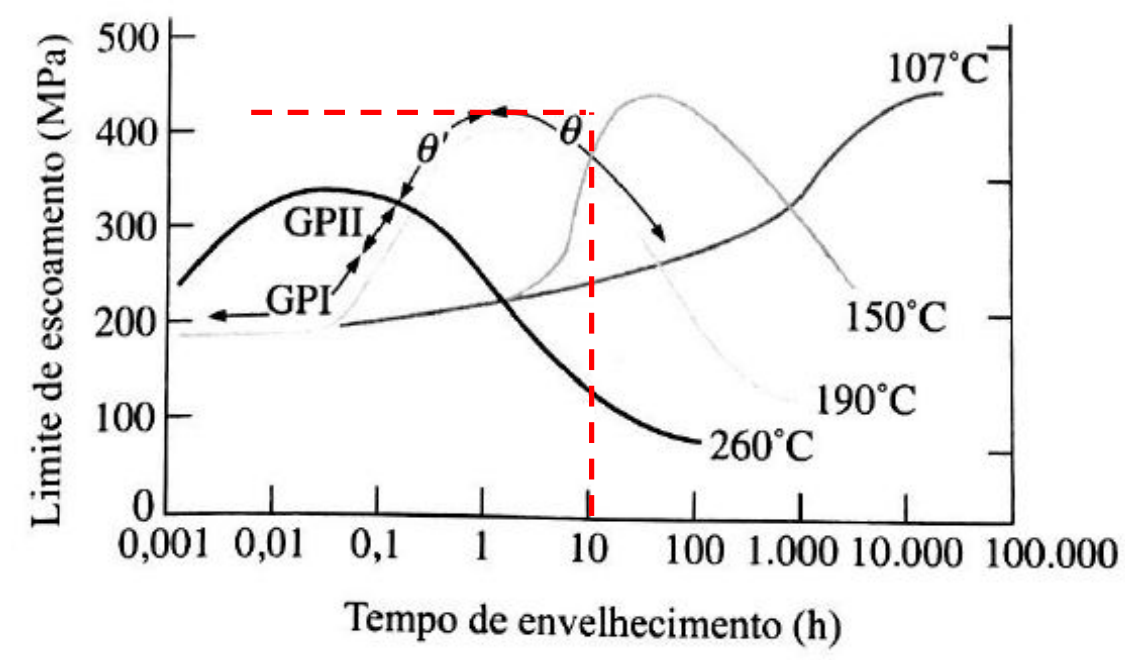

Para tanto, o objetivo deste trabalho é estudar a redução do tempo de envelhecimento, a partir da aplicação de altas temperaturas, na propriedade de dureza da liga Al 7075. Também será avaliada a microestrutura resultante do tratamento térmico de envelhecimento T6 modificado pelas características morfológicas microestruturais, buscando sua correlação com a literatura e correspondência com valores de dureza.

\section{MATERIAIS E MÉTODOS}

A metodologia aplicada ao estudo, segue o fluxograma mostrado na Figura 4, onde se utilizou a liga de alumínio Al 7075 sob duas condições: somente laminada e o mesmo material forjado. Amostras da chapa laminada e do componente forjado foram tratados termicamente e após foram realizadas análises metalográficas e de dureza. Por fim comparou-se os resultados aos resultados encontrados na literatura. 
Figura 4 - Fluxograma do trabalho desenvolvido.

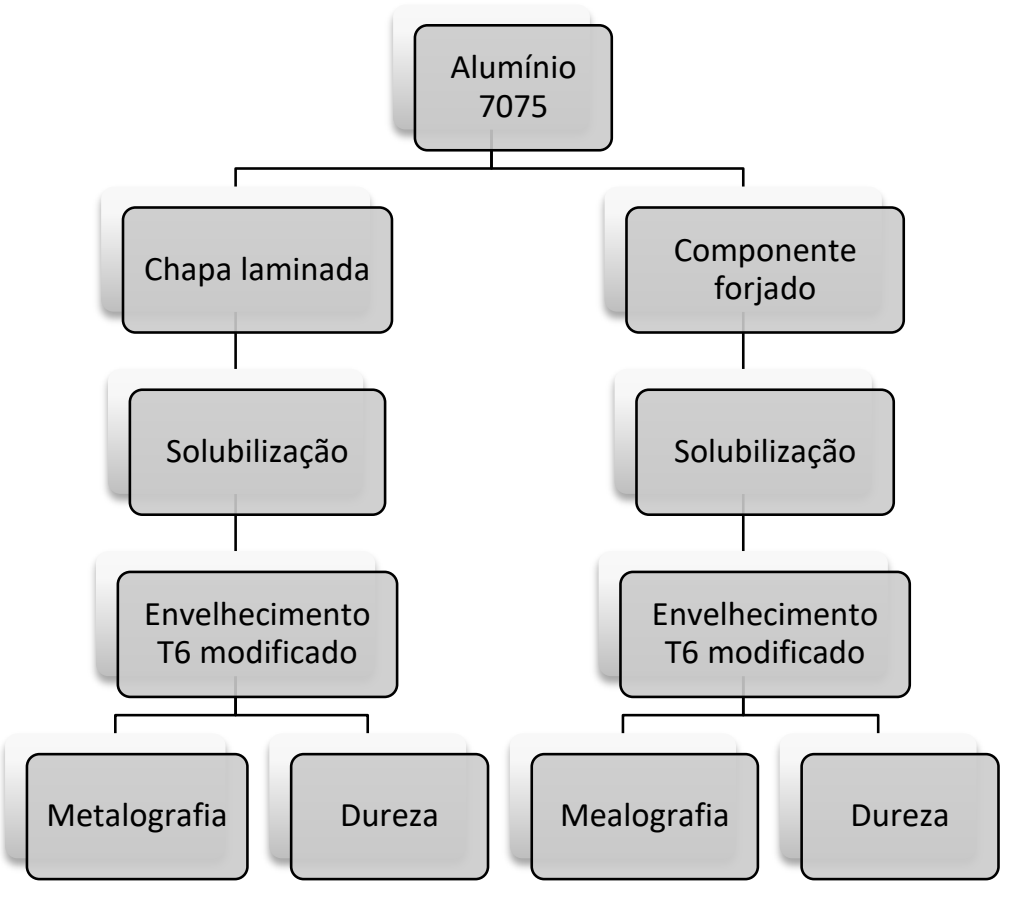

\section{SOLUBILIZAÇÃO}

O tratamento térmico das amostras foi realizado em forno Mufla préaquecido a $470^{\circ} \mathrm{C}$. Para facilitar a remoção das amostras, elas foram previamente amarradas com arame de aço, permitindo sua remoção simultânea com a pinça tenaz. Em frente ao forno foi posicionado um vasilhame com água à temperatura ambiente, para realizar o resfriamento brusco das amostras.

As amostras permaneceram no forno por 120 minutos e após foram rapidamente removidas e imersas na água, onde permaneceram por 5 minutos, garantindo seu completo resfriamento. Após as amostras foram armazenadas em refrigerador, com temperatura inferior a zero grau Célsius, para evitar o envelhecimento natural.

\section{TRATAMENTO TÉRMICO T6 MODIFICADO}

O envelhecimento também foi realizado em forno Mufla, onde se procedeu o pré-aquecimento à temperatura de $200^{\circ} \mathrm{C}$. As amostras foram introduzidas no forno, de forma similar ao caso antecedente, e mantidas no seu interior por $4 \mathrm{~h}$. Ao término, 
as mesmas foram retiradas do forno e alocadas sobre a bancada, para resfriamento ao ar ambiente.

\section{PREPARAÇÃO METALOGRÁFICA}

As amostras tratadas termicamente foram seccionadas em cortadora metalográfica, atentando-se para que fossem devidamente refrigeradas durante 0 corte. Todo esforço deve ser feito de modo que as amostras não sejam aquecidas durante o processo de preparação, pois isto pode modificar a microestrutura do material.

As amostras foram embutidas em resina polimérica, após lixadas e polidas pela sequência de passos conforme mostrado na Tabela 2.

Tabela 2 - Metodologia de Polimento

\begin{tabular}{l|c|c|c|c}
\hline Lixamento & Estágio & Estágio & Estágio & Estágio \\
\hline Granulometria & $\mathbf{1}$ & $\mathbf{2}$ & $\mathbf{3}$ & $\mathbf{4}$ \\
\hline Lubrificante & 180 & 400 & 600 & 1200 \\
\hline Força & água & água & água & água \\
\hline Tempo aproximado & 2 & 2 & 2 & 2 \\
\hline Polimento & Estágio & Manual & Manual & Manual \\
\hline Abrasivo & $\mathbf{1}$ & & \\
\hline Força & $\begin{array}{l}\text { Pasta de } \\
\text { diamante }\end{array}$ \\
\hline Tempo aproximado & Manual \\
\hline
\end{tabular}

Para análise microestrutural as amostras foram submetidas ao ataque químico, revelando assim a estrutura de contornos de grãos do material e as interfaces entre a matriz e os carbonetos. Para tal, utilizou-se como reagente ácido fosfórico $\left(\mathrm{H}_{3} \mathrm{PO}_{4}\right)$ 85\% PA, na concentração de 10\% em água destilada. $\mathrm{A}$ amostra deve ficar imersa na solução pelo período de 90 minutos, estando sua face voltada para cima. 


\section{ANÁLISE MICROESTRUTURAL}

O aspecto morfológico dos grãos, evidencias das diferentes fases, a distribuição de precipitados e defeitos microestruturais foram observados e registrados por meio de imagens via microscopia ótica.

A determinação do tamanho de grão foi realizada por meio das recomendações da norma ASTM E 112 (ASTM, 2013), método planimétrico. A análise é feita a partir da fotomicrografia dos grãos sob ampliação de 100x. A determinação do tamanho de grão é realizada pelas Equações 1 e 2.

$$
\begin{gathered}
N=2^{n-1} \\
n=\frac{\log N}{\log 2}+1
\end{gathered}
$$

Onde:

$N$ : é o número médio de grãos por polegada quadrada sob uma ampliação de 100x. $n$ : é o número do tamanho de grão.

\section{DUREZA}

A avaliação da dureza do material, após o tratamento térmico, foi realizada em um durômetro, pelo método Rockwell, escala B. Foram realizadas três medições em cada amostra, considerando-se a média entre elas como resultado. As amostras foram mantidas em temperatura ambiente de aproximadamente $22^{\circ} \mathrm{C}$, sendo avaliadas logo após resfriamento posterior ao processo de envelhecimento.

\section{RESULTADOS E DISCUSSÃO}

\section{ANÁLISE MICROESTRUTURAL DA LIGA AL 7075 SOLUBILIZADA}

A microestrutura das amostras da liga Al 7075 laminada e forjada e submetida ao tratamento de solubilização é mostrada na Figura 5. Nota-se os precipitados finamente dispersos (regiões escuras) na matriz (região clara). Cabe salientar que amostras solubilizadas geram tons esfumaçados, escurecendo totalmente a matriz. Destaca-se também a presença de inclusões, que segundo PONTES, 2017 são formadas ainda na fase de lingote, e não são dissolvidas no 
tratamento térmico. Trabalhos similares identificaram estes intermetálicos como

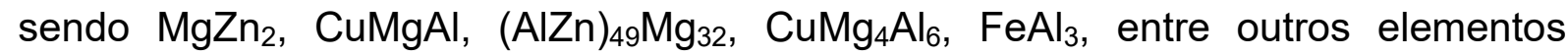
formados entre os elementos ligantes presentes na matriz.

Figura 5 - Microestrutura da liga Al 7075 após solubilização observada em microscópio ótico com aumento de 400X. (a) amostra laminada. (b) amostra forjada.

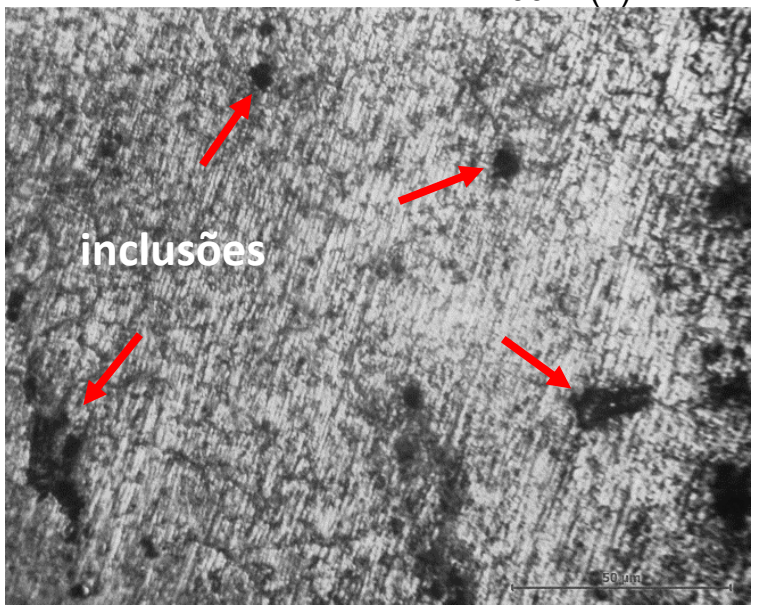

(a)

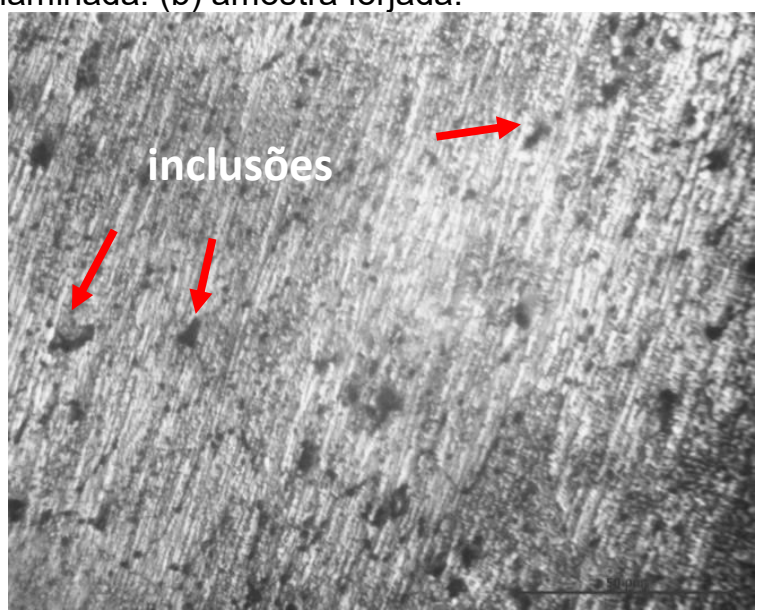

(b)

\section{ANÁLISE MICROESTRUTURAL DA LIGA AL 7075 ENVELHECIDA}

As imagens da Figura 6 mostram a microestrutura das amostras laminada e forjada que passaram pelo processo de envelhecimento à $200^{\circ} \mathrm{C}$ por 4 horas. Destaca-se nessas imagens o aparecimento dos contornos de grão, que nas amostras solubilizadas ficava dificultada sua visualização devido aos precipitados dispersos pela matriz.

Figura 6 - Microestrutura da liga Al 7075 após envelhecimento à $200^{\circ} \mathrm{C}$ por 4 horas, observada em microscópio ótico com aumento de 400X. (a) amostra laminada. (b) amostra forjada.

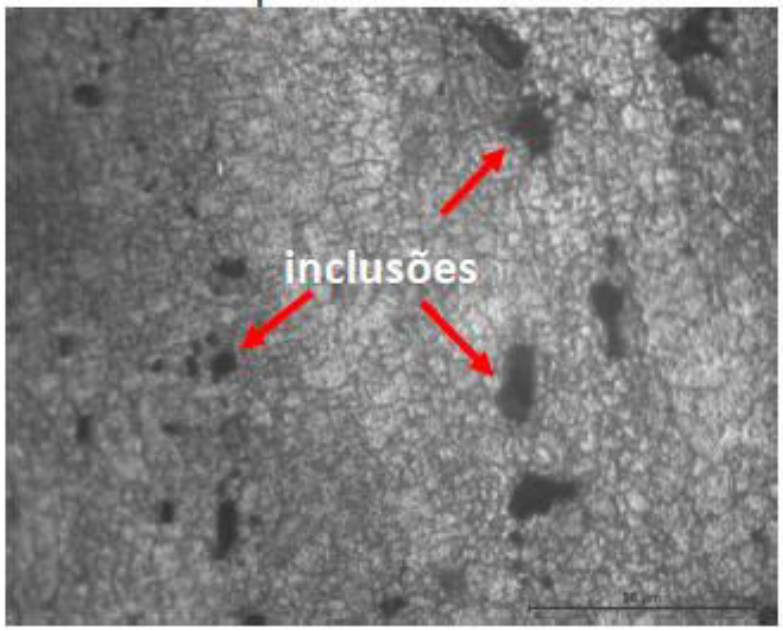

(a)

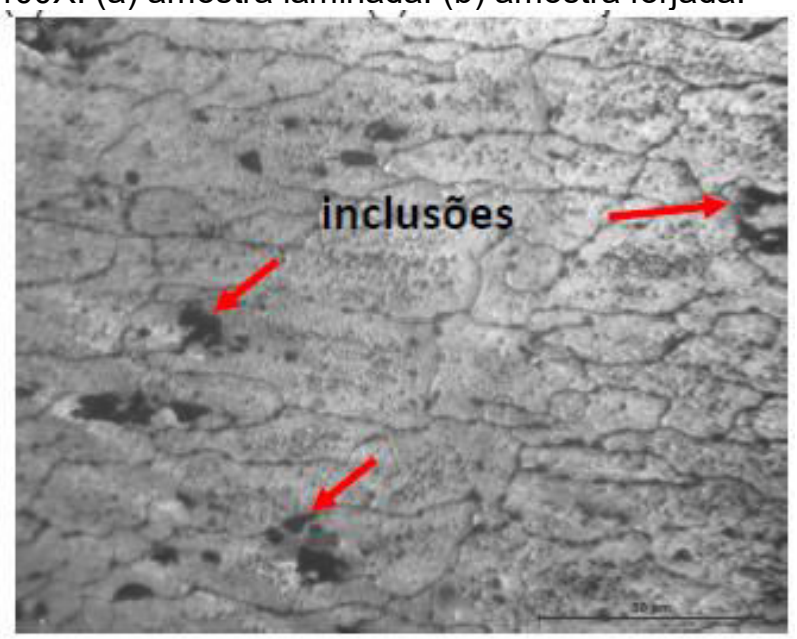

(b) 
A Figura 7, mostra de forma ampliada a amostra laminada, onde se vê a matriz com precipitados bem distribuídos ao longo dos grãos. Não foi possível a avaliação do tamanho de grão, pois o ataque não os revelou de forma completa, contudo fica evidente que são mais refinados do que a amostra forjada. Grãos refinados são característicos de materiais laminados e o forjamento gera aumento do tamanho de grão por implicar aumento de temperatura durante o processo.

O requisito geral para o endurecimento por precipitação envolve a formação de precipitados finamente dispersos durante o tratamento de envelhecimento. Quanto menos espaçados e menores forem os precipitados, maior será o aumento das propriedades mecânicas da liga, sem perda excessiva de ductilidade (ASM, 1992 a). A precipitação proveniente do processo de envelhecimento à $200^{\circ} \mathrm{C}$ por 4 horas gerou precipitados finos e amplamente dispersos no interior do grão.

Figura 7 - Amostra laminada ampliada.

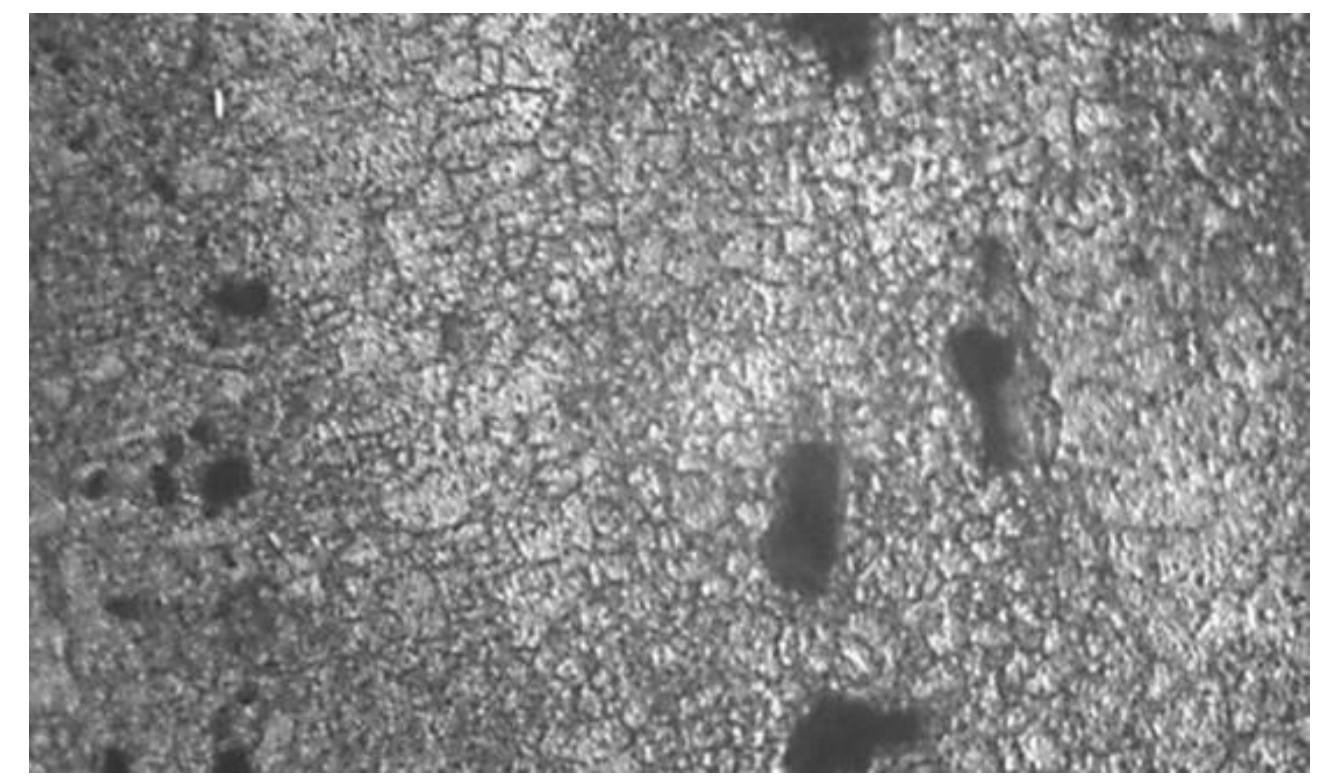

A Figura 8, mostra de forma ampliada a amostra forjada, onde se vê a matriz com precipitados bem distribuídos ao longo dos grãos. Os contornos de grão aparecem bem definidos e alongados. Houve formação de precipitados nos contornos de grão, não sendo interessante a presença de maiores quantidades desses precipitados pois pode resultar em fragilização do material com formação de microtrincas.

Observa-se também a formação de precipitados do tipo $\theta$, característicos pelo tamanho relativamente maior que os demais carbonetos finamente dispersos na matriz. O surgimento deste tipo de precipitado caracteriza que o material entrou na fase de superenvelhecimento, ou seja, o processo adotado levou o material além do 
pico máximo de resistência, ocasionando sua redução ao entrar nesse campo. A temperatura de $200^{\circ} \mathrm{C}$ e o tempo de 4 horas utilizados, podem resultar em superenvelhecimento, pois estão situados em região do gráfico (conforme visto na Figura 3), onde inicia a transição entre $\theta^{\prime}$ e $\theta$. Uma maneira de evitar a formação de carbonetos grosseiros (fase $\theta$ ) seria a utilização de uma temperatura pouco menor que $200^{\circ} \mathrm{C}$ ou a redução do tempo.

Figura 8 - Amostra forjada ampliada.

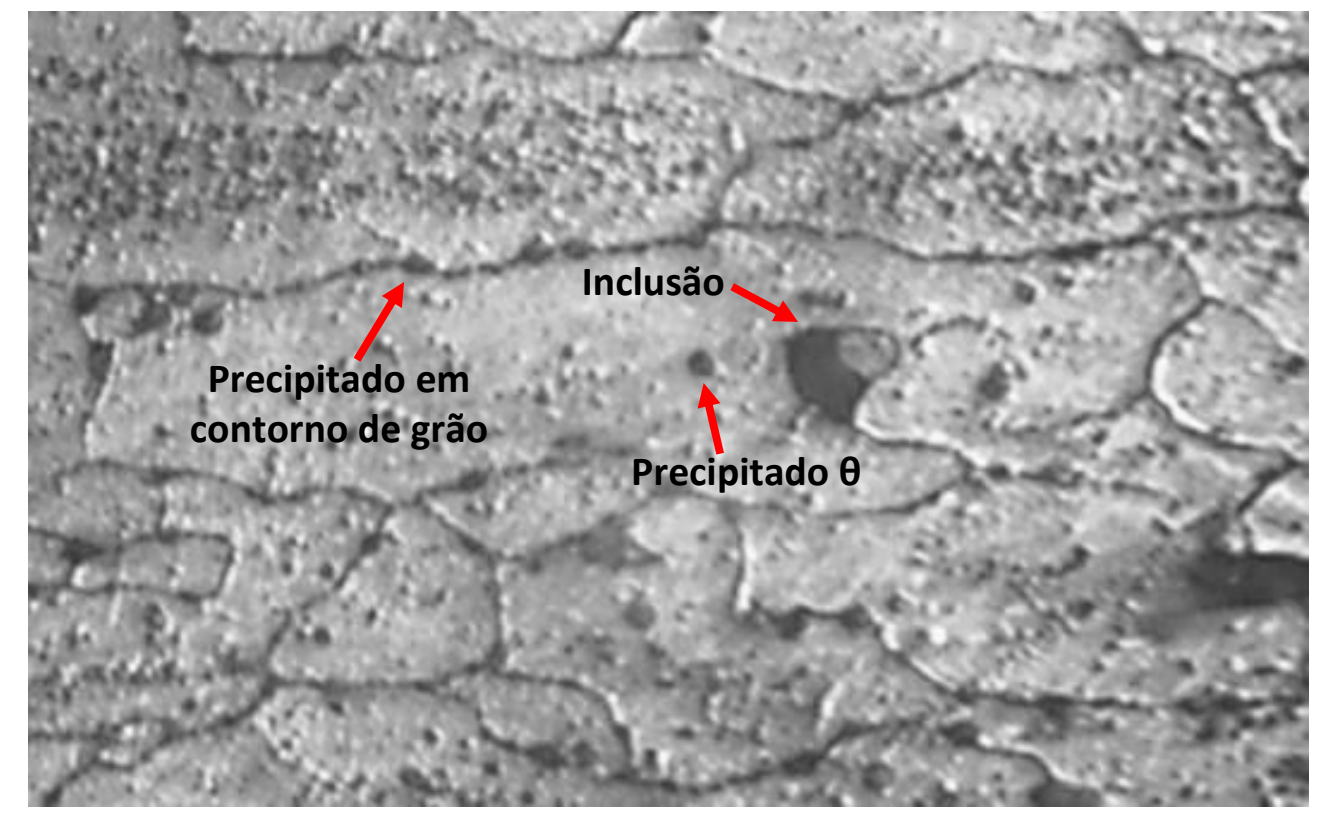

\section{ANÁLISE DO TAMANHO DE GRÃO}

Na Figura 9 é demonstrado o método utilizado na determinação do tamanho de grão da amostra forjada. Observa-se a quantidade de grãos contados em uma área delimitada por um quadrado de lado $100 \mu \mathrm{m}$, conforme método planimétrico da norma ASTM E112.

A determinação da quantidade de grãos por polegada quadrada foi obtida pela Equação 01, encontrando-se o valor de 5583,76. Após utilizou-se a Equação 02 para determinação do tamanho de grão médio, onde se obteve o valor de 13,44. 
Figura 9 - Representação da contagem de grãos para amostra forjada. Aumento $100 \mathrm{X}$.

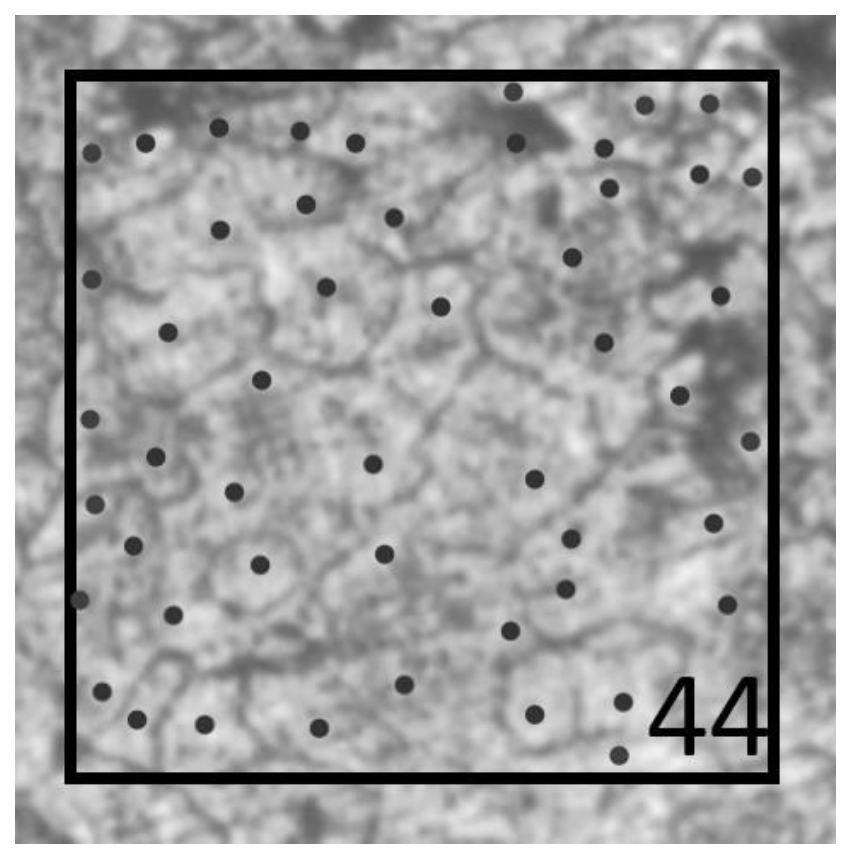

\section{DUREZA}

Os valores de dureza HRB podem ser observados na Figura 10, onde os valores de $A, B$ e $C$ são provenientes das amostras laminadas e os valores de $D, E$ e F são provenientes de amostras forjadas.

Figura 10 - Resultados das medições de dureza (HRB).

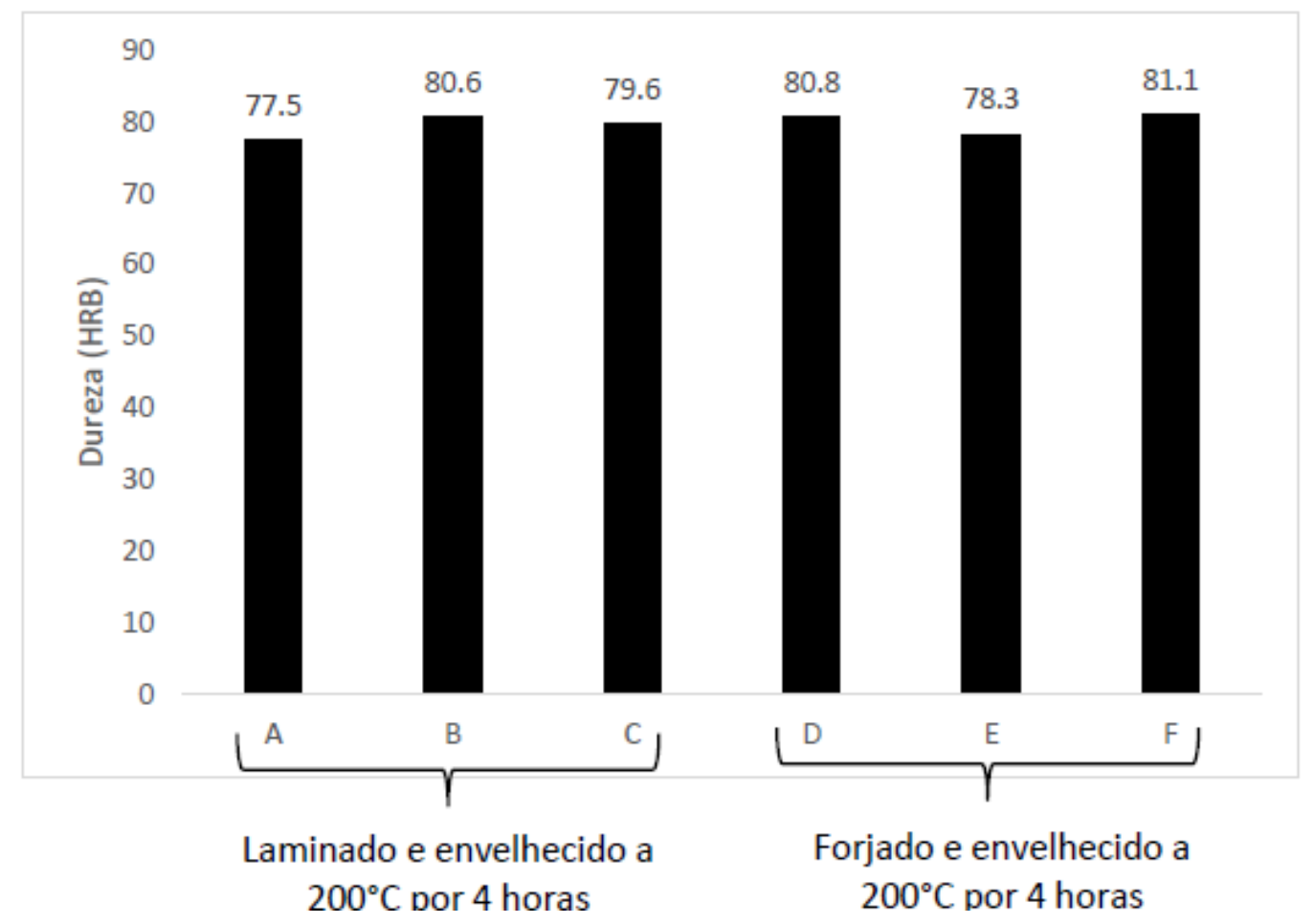


Observa-se que os valores obtidos em ambos os processos (laminado e forjado) são semelhantes, mesmo apresentando diferentes tamanhos de grãos. Isto ocorre por que a dureza da liga AL 7075 T6 está relacionada a distribuição homogênea de seus precipitados. Valores esperados para a liga AL 7075, após envelhecida pelo processo T6, são de 80 a 90 HRB (SILVA, 2016; PONTES, 2017). Valores de dureza próximos do mínimo esperado, corroboram com os resultados observados na Figura 9 que indicam o início do processo de superenvelhecimento, onde os precipitados começam a se concentrar nos contornos de grão, tornando-se mais grosseiros.

\section{CONCLUSÃO}

Baseado nos dados obtidos pelas técnicas experimentais empregadas e na literatura disponível pode-se concluir que os parâmetros do tratamento térmico de envelhecimento possuem grande influência na microestrutura do alumínio Al 7075.

O tempo de 4 horas provou ser o tempo limite para este tipo de procedimento, uma vez que a amostra já começa a apresentar superenvelhecimento.

A temperatura de envelhecimento de $200^{\circ} \mathrm{C}$ pelo tempo de 4 horas é capaz de garantir matriz com precipitados finamente dispersos, provendo à amostra dureza adequada (77 - $82 \mathrm{HRB})$.

A dureza obtida é compatível aos resultados de tratamentos de envelhecimento convencionais $\left(120^{\circ} \mathrm{C}\right.$ por 24 horas), podendo ser utilizado em aplicações industriais onde essa dureza é demandada, contudo, deve-se ter cautela para utilizações onde outras propriedades além da dureza são requeridas.

Estudos mais aprofundados são necessários para identificar este processo como sendo ideal para qualquer tipo de aplicação, uma vez que uma caracterização mais abrangente se faz necessária, como testes de fadiga, ensaio de tração, condutividade elétrica e suscetibilidade à corrosão. 


\section{REFERÊNCIAS}

ARAÚJO, D.; ROMERO, J.; MADANI, F.; BARBIERI, F. Estudo do envelhecimento artificial da liga de alumínio 7075. Universidade Paulista (UNIP), São Paulo, 2014

ASM. Handbook. Properties and selection. Nonferrous Alloys and SpecialPourpose Materials. Volume 2. ASM International Handbook Committe; USA Ohio, Materials Park, 1992 a.

ASM. Handbook. Properties and selection. Nonferrous Alloys and SpecialPourpose Materials. Volume 4. ASM International Handbook Committe; USA Ohio, Materials Park, 1992 b.

ASKELAND, D.; PHULÉ, P. Ciência e Engenharia dos Materiais. $1^{a}$ Ed. São Paulo, Cengage, 2008.

ASTM E112: Standard test Methods for determining average grains size. United States, 2013.

CHEN, S.; CHEN, K.; DONG, P.; YE, S.; HUANG, L. Effect of heat treatment on stress corrosion cracking, fracture toughness and strength of $\mathbf{7 0 8 5}$ aluminum alloy. Trans. Nonferrous Met. Soc. China (48), 2014: 2320-2325

HEALEY, J. Guinier-preston zone evolution in $\mathbf{7 0 7 5}$ aluminum. 1976 Tese de Doutorado, University of Florida.

HUANG Wen. Uniform Corrosion and General Dissolution of Aluminum Alloys 2024-73, 6061-T6, and 7075-T6. Ohio State University, 2006

KIECKOW, F.; MINOSSO, B.; PELLENZ, J. Influência da temperatura de envelhecimento nas propriedades da liga AL 7075. CRICTE, UNIJUÍ, Ijuí, 2017.

LI, J.; PENG, Z.; LI, C.; JLA, Z.; CHEN, W.; ZHENG, Z. Mechanical properties, corrosion behaviors and microstructures of 7075 aluminum alloy with various aging treatments. Trans. Nonferrous Met. Soc. China (18), 2008: 755-762

OLIVEIRA, G. Tratamento térmico de uma liga Al-Si-Mg-Mn. Dissertação apresentada ao programa de mestrado integrado em engenharia metalúrgica e de materiais. Portugal. Porto, 2012

SILVA, D. Estudo da cinética de envelhecimento e das propriedades mecânicas das ligas de alumínio 6061 e 7075 tratadas termicamente. Trabalho de conclusão apresentado ao departamento acadêmico de engenharia de materiais, UTFPR, Londrina, PR, 2016.

SMITH, W.F., Princípios de Ciência e Engenharia dos Materiais. McGRaw-Hill, Portugal, 1998. 
SOUZA, S. Ensaios mecânicos de materiais metálicos - fundamentos teóricos e práticos, 5ª Ed., São Paulo, Blucher, 1982.

PONTES, A. Análise da resistência à corrosão da liga de alumínio AA7075-T6 após conformação por laminação a frio. Dissertação apresentada ao programa de mestrado em projeto e fabricação. Minas Gerais, 2017.

ZOU, X.; YAN, H.; CHEN, X. Evolution of second phases and mechanical properties of $7075 \mathrm{Al}$ alloy processed by solution heat treatment. Trans.

Nonferrous Met. Soc. China (27), 2016: 2146-2155 